\title{
The anatomical relation of the extracranial internal carotid artery in the parapharyngeal space
}

\author{
Hanna J. Zająac ${ }^{1, A-D, F}$, Krzysztof Lachowski2,A-D,F, Agnieszka Lis'²,A-D,F, Tomasz Kręcicki ${ }^{1, A, C, E, F}$,

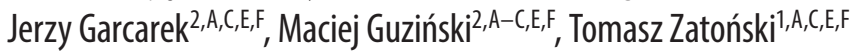 \\ ${ }^{1}$ Department of Otolaryngology, Head and Neck Surgery, Jan Mikulicz-Radecki University Teaching Hospital, Wroclaw Medical University, Poland \\ ${ }^{2}$ Department of Radiology, Interventional Radiology and Neuroradiology, Jan Mikulicz-Radecki University Teaching Hospital, Wroclaw Medical University, Poland \\ A - research concept and design; $B$ - collection and/or assembly of data; $C$ - data analysis and interpretation; \\ $D$ - writing the article; $E$ - critical revision of the article; $F$ - final approval of the article
}

Address for correspondence

Hanna Zając

E-mail:zajhanna@gmail.com

Funding sources

None declared

Conflict of interest

None declared

Acknowledgements

We would like to thank Błażej Owsiany for the statistical analysis of the collected data (Faculty of Mathematics and Computer Science, University of Wrockaw, Poland).

Received on April 25, 2017

Reviewed on September 6, 2017

Accepted on 0ctober 6, 2017

Published online on August 7, 2018

Cite as

Zając HJ, Lachowski K, Lis A, et al. The anatomical relation of the extracranial internal carotid artery in the parapharyngeal space. Adv Clin Exp Med. 2019;28(5):601-607. doi:10.17219/acem/78350

DOI

10.17219/acem/78350

\section{Copyright}

Copyright by Author(s)

This is an article distributed under the terms of the

Creative Commons Attribution Non-Commercial License

(http://creativecommons.org/licenses/by-nc-nd/4.0/)

\section{Abstract}

Background. The proximity of the internal carotid artery to the pharyngeal wall poses a risk of injury during nasopharyngeal surgery.

Objectives. The aim of this study was to assess the distances between the extracranial internal carotid artery (ICA) and the pharyngeal wall.

Material and methods. Measurements were taken on certain levels of the pharynx using computed tomography angiography (angio-CT) scans of 97 patients. One-tailed Student's t-test for independent variables and a comparison of expected values for dependent pairs of observations were applied.

Results. The shortest distance between the ICA and the pharyngeal wall was $1.1 \mathrm{~mm}$. The ICA is closer to the pharyngeal wall at the epiglottis apex level $(16.46 \pm 0.89 \mathrm{~mm})$ than to the Eustachian tube (ET) $(19.8 \pm 0.62 \mathrm{~mm})(p<0.0005)$. In women, the ICA is closer to the ET $(19.44 \pm 0.78 \mathrm{~mm})$ than in men $(20.17 \pm 0.96 \mathrm{~mm})(p=0.04)$. In women, the right ICA is closer to the pharyngeal wall than the left ICA at the level of the lower margin of the $2^{\text {nd }}$ cervical corpus vertebra (C2) (right: $17.6 \pm 1.8 \mathrm{~mm}$; left: $20.7 \pm 1.7 \mathrm{~mm}$ ) ( $p=0.002$ ) and at the level of the epiglottis apex (right: $15.2 \pm 1.7 \mathrm{~mm}$; left: $17.4 \pm 1.4 \mathrm{~mm}$ ) $(p=0.028)$. The bifurcation of the common carotid artery (CCA) is higher in men $(19.48 \pm 2.19 \mathrm{~mm}$ below the $(2)$ than in women $(21.82 \pm 1.02 \mathrm{~mm})(p<0.001)$. When the bifurcation is at the level of the epiglottis apex, the ICA is closer to the pharyngeal wall $(12.3 \pm 1.69 \mathrm{~mm})$ than in other cases $(16.46 \pm 0.89 \mathrm{~mm})$ $(p=0.005)$. In men, the higher the bifurcation is, the closer the ICA is to the pharyngeal wall at the level of the lower margin of the $C 2(p=0.003)$.

Conclusions. The risk of ICA incision during surgery differs between the pharyngeal levels, genders and sides of the neck. The ICA may be much closer to the pharyngeal wall than described in the literature.

Key words: common carotid artery, internal carotid artery, otorhinolaryngologic surgical procedures, Eustachian tube 


\section{Introduction}

The extracranial internal carotid artery (ICA) begins as an extension of the common carotid artery (CCA). It runs in the parapharyngeal space in an S-shaped course, then bends medially and heads toward the external opening of the carotid channel on the temporal bone. The distance from the ICA to the palatine tonsil has a mean value of $10-20 \mathrm{~mm}$ posteriorly,whereas it is $23.5 \mathrm{~mm}$ from the Eustachian tube (ET). ${ }^{1,2}$

Cases of ICA incision during tonsillectomy and adenoidectomy followed by a severe hemorrhage have been reported in the literature. ${ }^{3-5}$ Although many anatomical variations of this artery have already been described, only a few applicable and accurate pieces of information about the topography of the ICA have been provided. ${ }^{2,6-12}$

The aim of our study was to assess the distances between the ICA and the pharyngeal wall as well as to define their correlation with sex.

\section{Material and methods}

The presented work is a retrospective study, based on the computed tomography angiography (angio-CT) scans ( $0.625 \mathrm{~mm}$ resolution) of 97 patients (Table 1 ) performed between January 2013 and January 2015 in the Jan MikuliczRadecki University Teaching Hospital in Wrocław, Poland.

The scans were obtained with a LightSpeed VCT 64-slice CT scanner (GE Healthcare, Milwaukee, USA). The examined area covered the whole neck from the upper thorax to the base of the skull.

In all cases, the slice thickness was $0.67 \mathrm{~mm}$, the pitch amounted to 0.9 and the average gantry rotation time was $0.5 \mathrm{~s}$. The contrast agent bolus was administered using an automatic syringe. Vascular access was obtained with an $18 \mathrm{G}$ or $20 \mathrm{G}$ needle inserted into the ulnar vein. The volume of iodinated contrast agent ranged from 60 to $90 \mathrm{~mL}$. The rate of contrast agent administration was 4.0-4.5 mL/s. Contrast medium administration was followed by an injection of $40 \mathrm{~mL}$ of physiological salt solution. Automatic bolus tracking was performed in all cases, with a peak enhancement of $150 \mathrm{HU}$; scanning was automatically initiated after that. The obtained scans were analyzed using a dedicated workstation (AW4.4; GE Healthcare). Image postprocessing techniques involved

Table 1. The number, age and sex of the studied subjects

\begin{tabular}{|l|c|c|c|}
\hline \multicolumn{1}{|c|}{ Group } & Number & Mean age & SD \\
\hline All & 97 & 51.8 & 3.6 \\
\hline Women & 49 & 50.7 & 5.3 \\
\hline Men & 48 & 53.0 & 4.8 \\
\hline Group X & 12 & 48.7 & 8.5 \\
\hline
\end{tabular}

Group X - people with the common carotid artery bifurcation on the level of the epiglottis apex; SD - standard deviation.
2- and 3-dimensional reconstructions (Maximum Intensity Projection - MIP; Volume Rendering - VR).

The following distances were measured:

- the distance between the ICA ambit and the deepest visible point of the Eustachian Tube (ET) opening (Fig. 1);

- the distance between the ICA ambit and the pharyngeal wall at the level of the lower margin of the $2^{\text {nd }}$ cervical vertebra (C2) (Fig. 2);

- the distance between the ICA ambit and the pharyngeal wall at the level of the epiglottis apex (Fig. 3); and

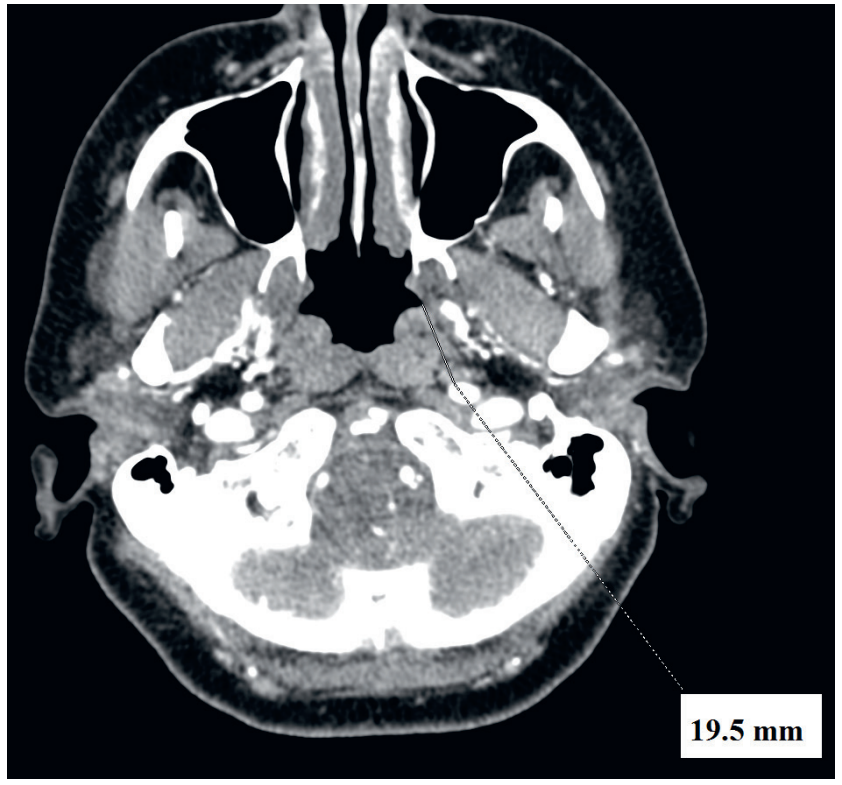

Fig. 1. Example of measuring the distance between the ICA ambit and the deepest visible point of the ET opening (left side: $19.5 \mathrm{~mm}$ )

ET - Eustachian tube; ICA - extracranial internal carotid artery.

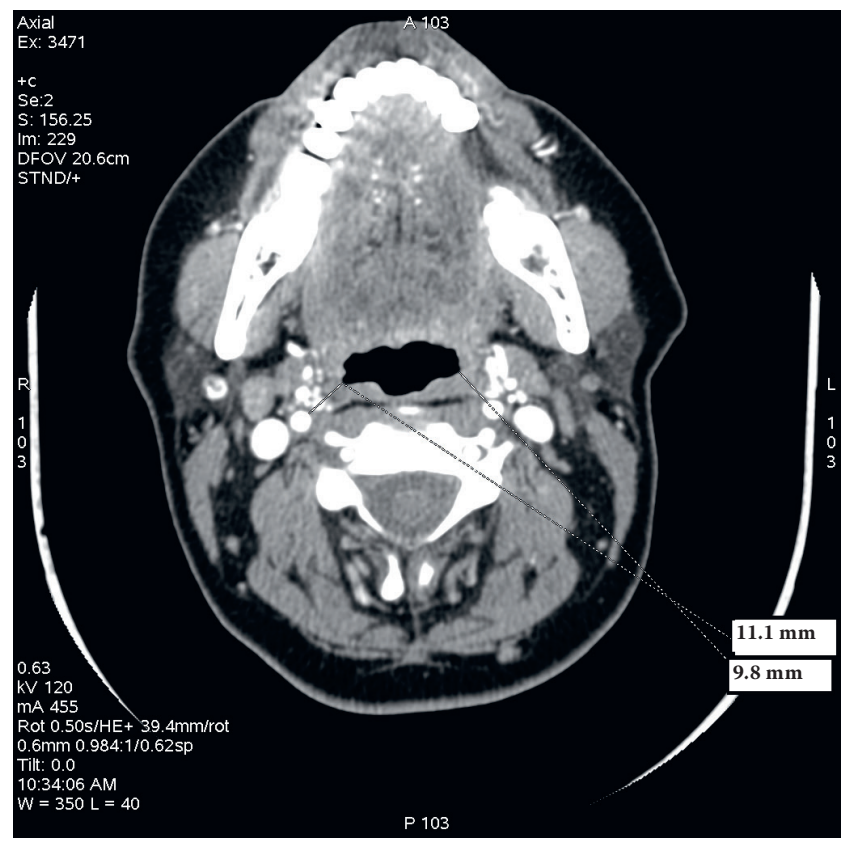

Fig. 2. Example of measuring the distance between the ICA ambit and the pharyngeal wall at the level of the C2 lower margin (right side: $11.1 \mathrm{~mm}$; left side: $9.8 \mathrm{~mm}$ )

C2 - $2^{\text {nd }}$ cervical vertebra; ICA - extracranial internal carotid artery. 


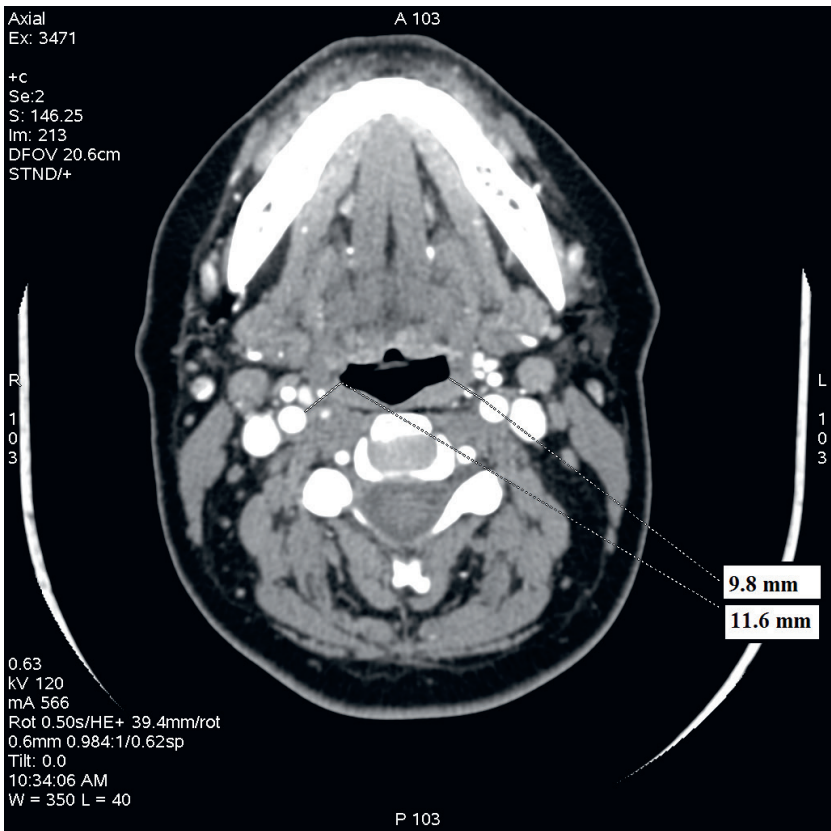

Fig. 3. Example of measuring the distance between the ICA ambit and the pharyngeal wall at the level of the epiglottis apex (right side: $11.6 \mathrm{~mm}$; left side: $9.8 \mathrm{~mm}$ )

ICA - extracranial internal carotid artery.

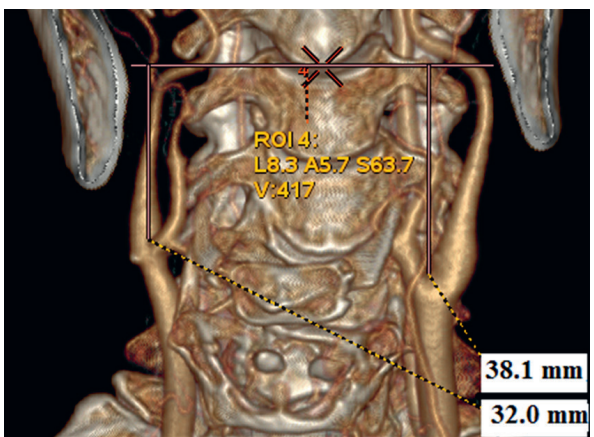

Fig. 4. Example of measuring the distance between the CCA bifurcation and the C2 lower margin (right side: $32.0 \mathrm{~mm}$; left side: $38.1 \mathrm{~mm}$ )

\section{CCA - common carotid artery; C2 - $2^{\text {nd }}$ cervical vertebra.}

- the distance between the CCA bifurcation and the lower margin of the $2^{\text {nd }} \mathrm{C} 2$ (Fig. 4).

Scans with a motion artifact, with masses that could cause dislocation of the artery or with damage to the facial bones were excluded. Only scans of good and very good opacification of the ICA were analyzed.

The values were compared using 1-tailed Student's t-test for independent variables and a comparison of expected values for dependent pairs of observations.

\section{Results}

The shortest distance found between the ICA and the pharyngeal wall was $1.1 \mathrm{~mm}$ (Fig. 5).

In 11 arteries, the closest distance to the pharyngeal wall along the whole course of the artery was found at Rosenmüller's fossa (mean: $3.74 \pm 1.2 \mathrm{~mm}$; min: $1.4 \mathrm{~mm}$ ) (Fig. 6).

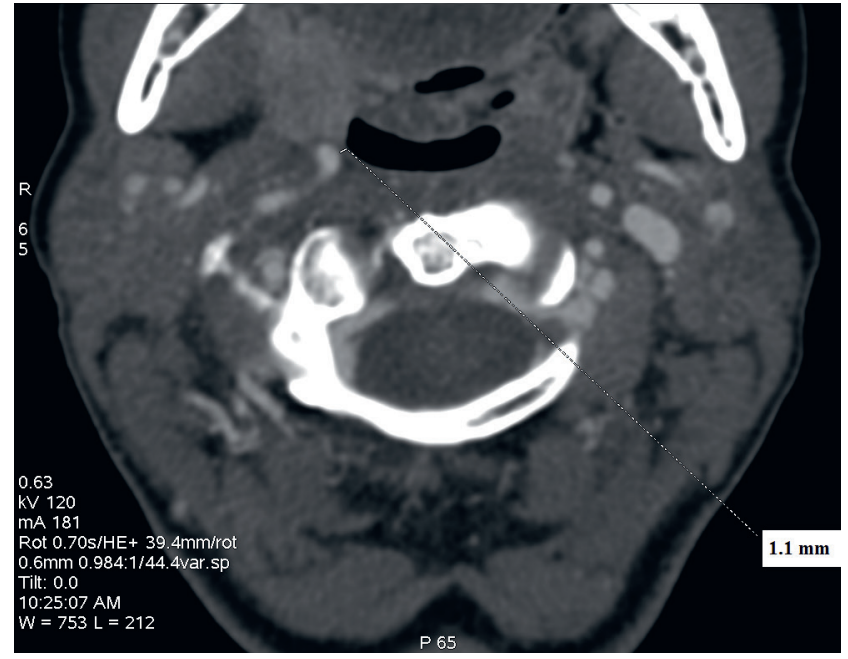

Fig. 5. The shortest distance found between the ICA and the pharyngeal wall: $1.1 \mathrm{~mm}$

\section{ICA - extracranial internal carotid artery.}

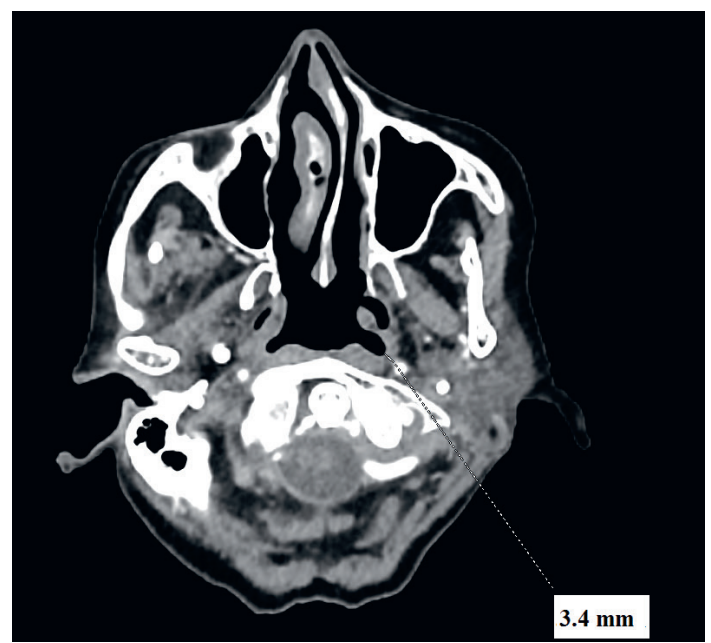

Fig. 6. Patient with a very small distance $(3.4 \mathrm{~mm})$ between the internal carotid artery and RF

RF - Rosenmüller's fossa.

\section{The pharynx levels}

The ICA is closer to the pharyngeal wall at the level of the epiglottis apex $(16.46 \pm 0.89 \mathrm{~mm})$ than to the ET $(19.8 \pm 0.62 \mathrm{~mm})(\mathrm{p}<0.0005)$ in both genders (Table 2$)$. In women, the ICA is closer to the ET $(19.49 \pm 0.78 \mathrm{~mm})$ than in men $(20.17 \pm 0.49 \mathrm{~mm})(\mathrm{p}=0.04)$ (Table 2$)$.

\section{The side of the neck}

In women, at the level of the lower margin of the $\mathrm{C} 2$, the distance between the ICA and the pharyngeal wall was shorter on the right side $(17.6 \pm 1.8 \mathrm{~mm})$ than on the left side $(20.7 \pm 1.7 \mathrm{~mm})(\mathrm{p}=0.002)$ (Table 3$)$. In women, at the level of the epiglottis apex, the distance between the ICA and the pharyngeal wall was shorter on the right side $(15.2 \pm 1.7 \mathrm{~mm})$ than on the left side $(17.4 \pm 1.4 \mathrm{~mm})$ 
Table 2. Distance between the ICA and the pharyngeal wall at different levels of the pharynx

\begin{tabular}{|c|c|c|c|c|}
\hline Group & Mean $[\mathrm{mm}]$ & $\mathrm{SD}$ & $\operatorname{Min}[\mathrm{mm}]$ & $\operatorname{Max}[\mathrm{mm}]$ \\
\hline \multicolumn{5}{|c|}{ A. Distance between the ICA ambit and the ET opening } \\
\hline All & 19.8 & 0.6 & 9.7 & 31.1 \\
\hline Women & 19.4 & 0.8 & 9.7 & 30.5 \\
\hline Men & 20.2 & 1.0 & 9.7 & 31.1 \\
\hline Group X & 19.1 & 1.9 & 10.7 & 23.5 \\
\hline \multicolumn{5}{|c|}{ B. Distance between the ICA and the pharyngeal wall at the level of the C2 lower margin } \\
\hline All & 19.4 & 1.0 & 4.7 & 37.9 \\
\hline Women & 19.1 & 1.4 & 4.7 & 35.9 \\
\hline Men & 19.8 & 1.5 & 5.1 & 37.9 \\
\hline Group X & 20.8 & 2.6 & 7.1 & 28.1 \\
\hline \multicolumn{5}{|c|}{ C. Distance between the ICA and the pharyngeal wall at the level of the epiglottis apex } \\
\hline Women & 16.2 & 1.1 & 2.5 & 30.6 \\
\hline Men & 16.7 & 1.4 & 6.6 & 33.3 \\
\hline Group X & 12.3 & 1.7 & 5.0 & 13.7 \\
\hline
\end{tabular}

Group X - people with the common carotid artery bifurcation on the level of the epiglottis apex; C2 - $2^{\text {nd }}$ cervical vertebrae; ET - Eustachian tube; ICA - extracranial internal carotid artery; SD - standard deviation.

Table 3. Distances between the right and left ICA and the pharyngeal wall at different pharynx levels in women

\begin{tabular}{|l|c|c|c|c|}
\hline \multicolumn{1}{|c|}{ Type of distance } & Right & SD & Left & SD \\
\hline $\begin{array}{l}\text { Distance between the ICA and the } \\
\text { pharyngeal wall at the level of the } \\
\text { C2 lower margin }\end{array}$ & 17.6 & 1.8 & 20.7 & 1.7 \\
\hline $\begin{array}{l}\text { Distance between the ICA and the } \\
\text { pharyngeal wall at the level of the } \\
\text { epiglottis apex }\end{array}$ & 15.2 & 1.7 & 17.4 & 1.4 \\
$\begin{array}{l}\text { The minimal distance of the ICA } \\
\text { to the pharyngeal wall along its } \\
\text { course between the epiglottis apex } \\
\text { and the ET }\end{array}$ & 10.6 & 1.5 & 13.3 & 1.9 \\
\hline
\end{tabular}

C2 - $2^{\text {nd }}$ cervical vertebra; ET - Eustachian tube; ICA - extracranial internal carotid artery; SD - standard deviation.

$(\mathrm{p}=0.028)$ (Table 3). The minimal distance of the ICA to the pharyngeal wall along its whole course between the epiglottis apex and the ET was smaller in women on the right side $(10.55 \pm 1.5 \mathrm{~mm})$ than on the left side $(13.3 \pm 1.9 \mathrm{~mm})(\mathrm{p}=0.015)$ (Table 3$)$. Men showed no asymmetry in any measurements.

\section{The common carotid artery bifurcation}

The bifurcation of the CCA is located closer to the C2 lower margin in men $(19.48 \pm 1.12 \mathrm{~mm})$ than in women $(21.82 \pm 1.02 \mathrm{~mm})(\mathrm{p}<0.001)$ (Table 4). In men, the higher the CCA bifurcation is, the closer the ICA is to the pharyngeal wall at the level of the $C 2$ lower margin $(p=0.003)$ (Table 4).
Table 4. Distance between the CCA bifurcation and the C2 lower margin

\begin{tabular}{|l|c|c|c|c|}
\hline \multicolumn{1}{|c|}{ Group } & $\begin{array}{c}\text { Mean distance } \\
{[\mathrm{mm}]}\end{array}$ & SD & $\begin{array}{c}\text { Min distance } \\
{[\mathrm{mm}]}\end{array}$ & $\begin{array}{c}\text { Max distance } \\
{[\mathrm{mm}]}\end{array}$ \\
\hline All & 20.8 & 1.5 & $-15.0^{*}$ & 48.6 \\
\hline Women & 21.8 & 1.0 & 3.0 & 48.3 \\
\hline Men & 19.5 & 2.2 & $-15.0^{*}$ & 48.6 \\
\hline Group X & 13.3 & 4.1 & $-15.0^{*}$ & 33.1 \\
\hline
\end{tabular}

Group X - people with the CCA bifurcation at the level of the epiglottis apex; CCA - common carotid artery; $C 2-2^{\text {nd }}$ cervical vertebra; SD - standard deviation; *15 mm above the C2 lower margin.

\section{Group X}

We found 12 patients (group X: 8 men and 4 women; mean age: $48.7 \pm 8.5$ years) who had the CCA bifurcation at the level of the epiglottis. In group $\mathrm{X}$, the distance between the ICA and the pharyngeal wall at the level of the epiglottis apex was significantly lower $(12.29 \pm 1.68 \mathrm{~mm})$ than in the rest of our study group $(16.54 \pm 0.98 \mathrm{~mm})$ $(\mathrm{p}=0.005)$.

\section{Discussion}

\section{The difference between genders}

The ICA was closer to the ET in the case of women $(\mathrm{p}=0.04)$, although at any other level of the pharynx, no such dissimilarity between genders was found. The ET is located near the entrance of the ICA into the external opening of the carotid artery canal in the temporal bone. As the female skull is smaller than the male one, the position 
of the canal may cause moving of the ICA closer to the medial line of the body, and therefore shortening of its distance to the pharyngeal wall. ${ }^{13}$ In the middle course of the ICA, where no difference between genders was revealed, the impact of the muscle mass and tension is diverse.

Bergin et al. reported that the distance between the ICA and the ET was shorter in women, which is in line with our study. ${ }^{2}$ However, Jun et al. reported that at all levels of the pharynx, the distances from the ICA to the pharyngeal wall were shorter in women. ${ }^{11}$

\section{Asymmetry}

The distance of the ICA to the pharyngeal wall at the $\mathrm{C} 2$ level $(\mathrm{p}=0.002)$, at the level of the epiglottis apex $(\mathrm{p}=0.028)$, and the minimal distance in the course between the epiglottis apex and the ET $(\mathrm{p}=0.015)$ are all shorter on the right side for women. An analysis of the CCA origin on both sides may provide an explanation for this difference. The right CCA starts in the bifurcation of the brachiocephalic trunk, whereas the left one begins at the aortic arch and runs in its pectoral part in an oblique direction and to the left. ${ }^{1}$ The brachiocephalic trunk runs steeper than the aortic arch, and therefore allows the right CCA (and thus the right ICA) to branch closer to the medial line than the left ICA. The left CCA is also shifted toward the left side in its pectoral part due to the position of the heart.

There is no difference between the left and the right distance between the ICA and the ET. We assume that this is caused by the symmetry of the external carotid canal openings in the skulls of both men and women, hence the artery is forced by their position to change its position in relation to the medial line, and thus to the pharyngeal wall. ${ }^{14}$

Men presented no asymmetry in any of the abovementioned measurements.

\section{The common carotid artery bifurcation}

The CCA bifurcation is usually situated at the level of the upper part of the $4^{\text {th }}$ cervical vertebra (C4) or the lower part of the $3^{\text {rd }}$ cervical vertebra (C3). Less than $1 \%$ of people are thought to have the bifurcation at the level of the $\mathrm{C} 2$, although such cases have been reported in the literature. . $15,16^{-11}$

One of the examined patients had the CCA bifurcation $15 \mathrm{~mm}$ above the $\mathrm{C} 2$ lower margin; therefore, only the CCA was present in the oropharynx.

According to our study, the CCA bifurcation is closer to the C2 lower margin in men $(19.48 \pm 1.12 \mathrm{~mm})$ than in women $(21.82 \pm 1.02 \mathrm{~mm})(\mathrm{p}<0.001)$.

In men, the higher the CCA bifurcation is, the closer the ICA is to the pharyngeal wall at the level of the C2 lower $\operatorname{margin}(\mathrm{p}=0.003)$.
In group $\mathrm{X}$, the ICA was closer to the pharyngeal wall at the level of the epiglottis apex $(12.29 \pm 1.68 \mathrm{~mm})$ than in the rest of the study group $(16.54 \pm 0.98 \mathrm{~mm})(\mathrm{p}=0.005)$. This may be caused by the widening of the CCA in the area of the bifurcation. ${ }^{17}$

The distance between the ICA and the pharyngeal wall at the level of the epiglottis apex is the most significant in reference to tonsillectomy, since it is very close to the level of the tonsillar fossa. If men are prone to having the CCA bifurcation higher than women, they are more exposed to the risk of fatal hemorrhage caused by an incision of the CCA. This danger is even more increased by the fact that if the ICA still does not branch at the level of the epiglottis apex, the CCA may be closer to the pharyngeal wall than the ICA would be at this level.

\section{The levels of the pharynx}

The ICA is closer to the pharyngeal wall at the level of the epiglottis apex than at the level of the ET $(p<0.0005)$. Therefore, only the measurements at the oropharynx can be taken into consideration while estimating the risk of arterial trauma during tonsillectomy, because the course of the ICA in the nasopharynx and oropharynx is divergent. Such reasoning can also be referred to the measurements made by Jun et al. ${ }^{11}$ The mean minimal distances in that study were $17.1 \pm 4.1 \mathrm{~mm}$ at the nasopharynx, $15.8 \pm 4.6 \mathrm{~mm}$ at the oropharynx and $13.5 \pm 6 \mathrm{~mm}$ at the hypopharynx. Those distances decreased significantly downward ( $\mathrm{p}<0.0001) .{ }^{18}$ However, Deutsch et al., who correlated the distance of the ICA to the ET with age and weight, formulated the conclusion that this parameter can be used to predict the distance from the tonsillar fossa to the ICA in children, whose anatomical relations in the nasopharynx are different than in adults. ${ }^{10}$

We discovered 11 arteries in which the minimal distance was at a very deep Rosenmüller's fossa (RF) (mean: $3.74 \pm 1.2 \mathrm{~mm}$; min: $1.4 \mathrm{~mm}$ ). This finding corresponds with the results of Bergin et al., who reported a possible shortening of the distance between the ICA and RF, with a minimal value of $0.2 \mathrm{~mm} .^{2}$ This should be kept in mind while performing adenoidectomy. During this procedure, the blade of the curette is pushed over toward the posterior nasopharyngeal wall. ${ }^{19}$

The average distance between the ICA and the ET was $19.8 \pm 0.62 \mathrm{~mm}$. Bergin et al. reported the mean distance to be $23.5 \mathrm{~mm}$, Lien et al. found $23.1 \pm 3.1 \mathrm{~mm}$ for nonaberrant arteries and $19.6 \pm 2.8 \mathrm{~mm}$ for aberrant arteries, and for Deutsch et al., it amounted to $25 \mathrm{~mm}$ in children 12 years in age or $56 \mathrm{~kg}$ in weight. ${ }^{2,10,12}$ The divergence probably occurs due to different measuring methods; the above-mentioned authors chose to determine the distance to the anterosuperior margin of the torus, located further from the ICA than our measuring point - the deepest part of the ET opening. 


\section{Age}

We compared the mean values of the measurements in several age groups (Fig. 7). The amount of data we had did not allow us to pursue a statistical analysis of the correlations between age and distance. Nevertheless, the mean minimal distance decreased from $13.8 \mathrm{~mm}$ in the 14-31 age group to only $9.5 \mathrm{~mm}$ in the $71-86$ age group. The literature suggests that the ICA may be closer to the pharyngeal wall in older people. ${ }^{11,12}$ The prevalence of the ICA morphological variations increases with age, which can cause a decrease in the distance to the pharyngeal wall. ${ }^{2,19-22}$

\section{Aberrations}

It is assumed that the ICA, which is a transition zone between a vessel of the elastic type (CCA) and the muscular type (intracranial ICA), is particularly susceptible to metaplastic transformations, leading to aberrations. ${ }^{5,20}$ Such transformations reduce the distance between the artery and the pharyngeal wall. 2,19,21,22 Pfeiffer and Ridder stated that the minimal distance between the aberrant vessels and the pharyngeal wall ranged from 0.8 to $17.9 \mathrm{~mm}$ (mean: $7.0 \mathrm{~mm}) .{ }^{23}$ Kinking and coiling of the ICA did not shorten the mean distances from the ICA to the nasopharyngeal walls. ${ }^{23}$ As the aberrations usually cause a medial curve of the ICA, it is advisable to be especially cautious while operating on patients with the specific features suggested by numerous studies as the risk factors for the presence of an aberrant ICA (Table 5).

Further studies should provide accurate data on the correlation between the position of the ICA in the parapharyngeal space with the abovementioned characteristics. It would help to estimate whether it is recommendable to perform radiological examination prior to tonsillectomy in some cases. The most accurate techniques for this purpose are believed to be time-of-flight magnetic resonance (MR) angiography or multiple detector computed tomography (MDCT). ${ }^{7,22}$ However, CT and MR angiographies, and the much cheaper Doppler ultrasonography (USG) were also used to define the position of the neck vessels. ${ }^{23-27}$

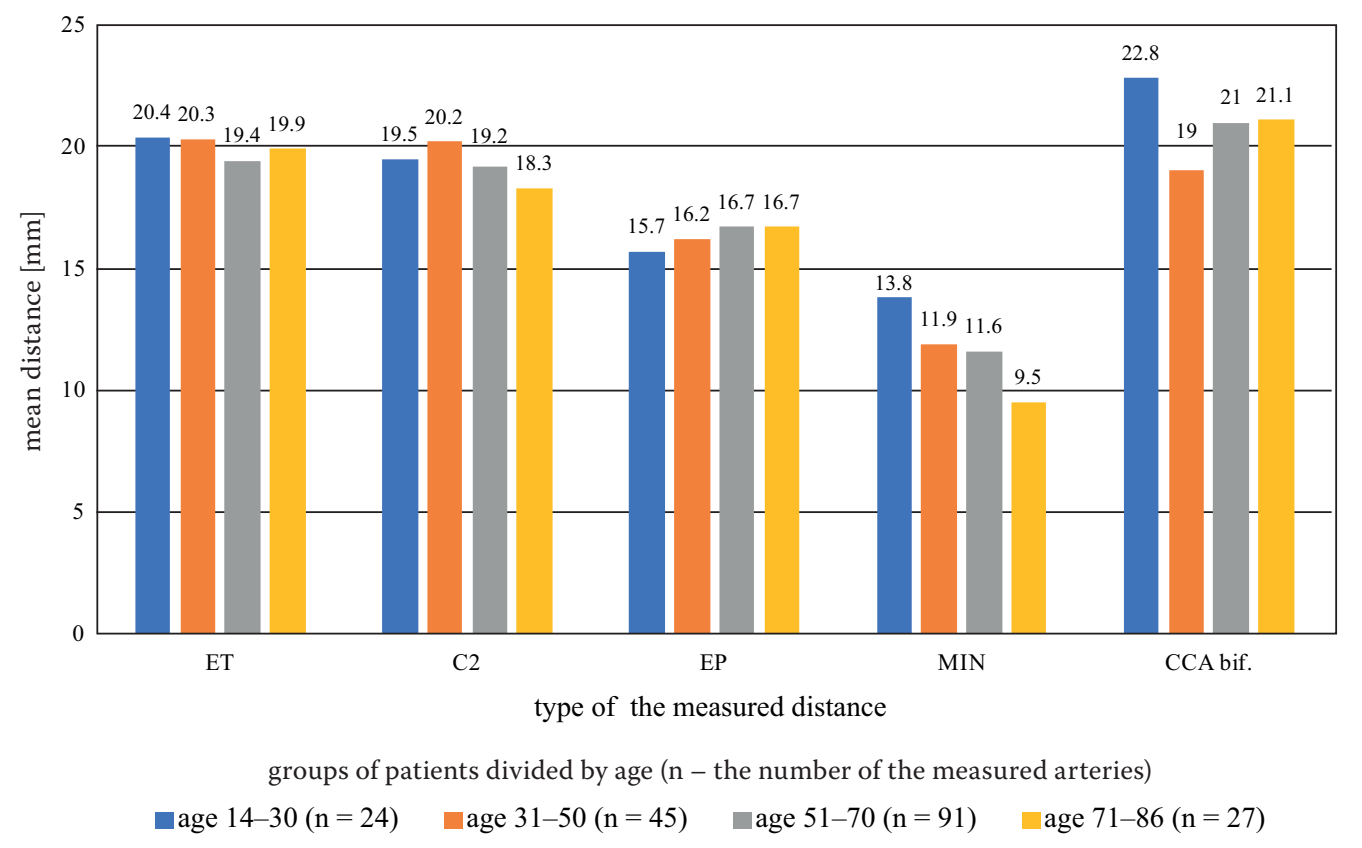

Fig. 7. Mean values of the measured distances in the chosen age groups

ET - distance between the ICA ambit and the deepest visible point of the ET tube opening; C2 - distance between the ICA ambit and the pharyngeal wall at the level of the lower margin of the $2^{\text {nd }}$ cervical vertebra; EP - distance between the ICA ambit and the pharyngeal wall at the level of the epiglottis apex; CCA bif. - distance between the common carotid artery bifurcation and the lower margin of the $2^{\text {nd }}$ cervical vertebra; MIN - minimal distance of the ICA to the pharyngeal wall found along its course between the Eustachian tube opening the epiglottis apex level; ICA - extracranial internal carotid artery.

Table 5. Predicted risk factors for the presence of an aberrant ICA or a decreased distance between the ICA and the pharyngeal wall

\begin{tabular}{|c|c|}
\hline Advanced age $e^{11,12}$ & Diabetes $^{26}$ \\
\hline Female sex ${ }^{11,12,26}$ & Cerebrovascular symptoms 24 denied by 25 \\
\hline Hypertension 26,27 & Cephalgia 23 \\
\hline Atherosclerosis 26 denied by 25 & Chronic infection of the tonsils (local spasm and thrombosis) ${ }^{5}$ \\
\hline Cardiovascular diseases 23 denied by 25 & Cervical dysesthesia ${ }^{23}$ \\
\hline Transient ischemic attacks ${ }^{23}$ & Cervical pain ${ }^{23}$ \\
\hline Difficulties with swallowing and speech ${ }^{23}$ & Pharyngeal pressure, foreign body sensations, intraoral pulsations ${ }^{23}$ \\
\hline Noise perceptions, dizziness, tinnitus ${ }^{23}$ & Glossopharyngeal neuralgia ${ }^{23}$ \\
\hline
\end{tabular}

ICA - extracranial internal carotid artery. 


\section{Conclusions}

In women, the ICA tends to be closer to the pharyngeal wall on the right side of the oropharynx; however, its distance to the ET is the same on both sides.

The ICA is closer to the pharyngeal wall in women than in men only at the level of the ET.

The ICA is closer to the pharyngeal wall at the level of the epiglottis apex than at the level of the ET; therefore, any measurements at the ET level are not representative of the distance between the ICA and the tonsillar fossa.

Patients with the CCA bifurcation at the level of the epiglottis apex have a shorter ICA distance to the pharyngeal wall at this level. Men have the CCA bifurcation higher than women, so they are more prone to CCA incision during surgery.

\section{References}

1. Bochenek A, Reicher M. Anatomia Człowieka. Tom III: Układ naczyniowy. [Human Anatomy. Vol. 3: Vascular System] $9^{\text {th }}$ ed. Warszawa, Poland: Wydawnictwo Lekarskie PZWL; 2012:181-182.

2. Bergin M, Bird P, Cowan I, Pearson JF. Exploring the critical distance and position relationships between the Eustachian tube and the internal carotid artery. Otol Neurotol. 2010;31(9):1511-1515.

3. Carvalho KS, Edwards-Brown M, Golomb MR. Carotid dissection and stroke after tonsillectomy and adenoidectomy. Pediatr Neurol. 2007; 37(2):127-129.

4. Windfuhr JP, Schloendorff G, Sesterhenn AM, Prescher A, Kremer B. A devastating outcome after adenoidectomy and tonsillectomy: Ideas for improved prevention and management. Otolaryngol Head Neck Surg. 2009;140(2):191-196.

5. Wraige E, Ganesan V, Pohl KR. Arterial dissection complicating tonsillectomy. Dev Med Child Neurol. 2003;45(9):638-639.

6. Agrawal R, Agrawal SK. Dangerous anatomic variation of internal carotid artery - a rare case report. International Journal of Anatomy Variations. 2011:4:174-176.

7. Cvetko E. Concurrence of bilateral kinking of the extracranial part of the internal carotid artery with coiling and tortuosity of the external carotid artery - a case report. Rom J Morphol Embryol. 2014;55(2): 433-435.

8. Galletti B, Bucolo S, Abbate G, et al. Internal carotid artery transposition as risk factor in pharyngeal surgery. Laryngoscope. 2002;112 (10):1845-1848.

9. Ovchinnikov NA, Rao RT, Rao SR. Unilateral congenital elongation of the cervical part of the internal carotid artery with kinking and looping: Two case reports and review of the literature. Head Face Med. 2007;3:29.
10. Deutsch MD, Kriss MK, Willging P. Distance between the tonsillar fossa and internal carotid artery in children. Arch Otolaryngol Head Neck Surg. 1995;121(12):1410-1412. doi: 10.1001/archotol.1995.01890120066013

11. Jun BC, Jeon EJ, Kim DH, et al. Risk factors for decreased distance between internal carotid artery and pharyngeal wall. Auris Nasus Larynx. 2012;39(6):615-619.

12. Lien CF, Weng HH, Lin BS, Liu CF, Wu TC, Lin YS. Effect of carotid artery aberrancy on the distance between the vessel and nasopharyngeal subsites. J Chin Med Assoc. 2014;77(5):253-257.

13. Salisbury E. Sex estimation using morphological traits of the skull. Poster session presented at: Academic Excellence Showcase. Western Oregon University; May 31, 2012; Monmouth, USA.

14. Shaikh VG, Kulkarni PR. A study of morphology, morphometry, symmetry and development of external opening of carotid canal with comparison in male, female and foetus. International Journal of Anatomy and Research. 2014;2(4):797-805.

15. Gluncic V, Petanjek Z, Marusic A, Gluncic I. High bifurcation of common carotid artery, anomalous origin of ascending pharyngeal artery and anomalous branching pattern of external carotid artery. Surg Radiol Anat. 2001;23(2):123-125.

16. Ozgur Z, Figen G, Ozgur T. Anatomic evaluation of the carotid artery bifurcation in cadavers: Implications for open and endovascular therapy. Surg Radiol Anat. 2008;30(6):475-480.

17. Schulz UG, Rothwell PM. Sex differences in carotid bifurcation anatomy and the distribution of atherosclerotic plaque. Stroke. 2001;32(7): 1525-1531.

18. Klosek KS, Rungruang T. Topography of carotid bifurcation: Considerations for neck examination. Surg Radiol Anat. 2008;30(5):383-387.

19. Myers EN. Operative Otolaryngology: Head and Neck Surgery. Vol. 1. $2^{\text {nd }}$ ed. Philadelphia, PA: Saunders/Elsevier; 2008.

20. La Barbera G, La Marca G, Martino A, et al. Kinking, coiling, and tortuosity of extracranial internal carotid artery: Is it the effect of a metaplasia? Surg Radiol Anat. 2006;28(6):573-580.

21. Ekici F, Tekbas G, Onder H, et al. Course anomalies of extracranial internal carotid artery and their relationship with pharyngeal wall: An evaluation with multislice CT. Surg Radiol Anat. 2012;34(7):625-631.

22. Paulsen F, Tillmann B, Christofides C, Richter W, Koebke J. Curving and looping of the internal carotid artery in relation to the pharynx: Frequency, embryology and clinical implications. J Anat. 2000;197(Pt 3): 373-381.

23. Pfeiffer J, Ridder GJ. A clinical classification system for aberrant internal carotid arteries. Laryngoscope. 2008;118(11):1931-1936.

24. Koskas F, Bahnini A, Walden R, Kieffer E. Stenotic coiling and kinking of the internal carotid artery. Ann Vasc Surg. 1993;7(6):530-540.

25. Togay-Işikay C, Kim J, Betterman K, et al. Carotid artery tortuosity, kinking, coiling: Stroke risk factor, marker, or curiosity? Acta Neurol Belg. 2005;105(2):68-72.

26. Macchi C, Gulisano M, Giannelli F, Catini C, Pratesi C, Pacini P. Kinking of the human internal carotid artery: A statistical study in 100 healthy subjects by echocolor Doppler. J Cardiovasc Surg (Torino). 1997;38(6): 629-637.

27. Pancera P, Ribul M, Presciuttini B, Lechi A. Prevalence of carotid artery kinking in 590 consecutive subjects evaluated by Echocolordoppler: Is there a correlation with arterial hypertension? J Intern Med. 2000;248(1):7-12. 